\title{
Microscopic and Molecular Detection of Theileria annulata Infection of Cattle in Egypt
}

\author{
Khaled Mohamed El-Dakhly ${ }^{*}$, Waleed Arafa ${ }^{1}$, Saad Soliman Ghanem², Omima Ramadan \\ Abdel-Fatah ${ }^{3}$, Ahmed Anwar Wahba ${ }^{4}$
}

${ }^{1}$ Department of Parasitology, Faculty of Veterinary Medicine, Beni-Suef University, Beni-Suef 62511, Egypt; ${ }^{2}$ Directorate of Veterinary Medicine, Veterinary Administration, El-Dakhla, El-Wadi El-Gadid, Egypt; ${ }^{3}$ Animal Health Research Institute, El-Fayoum, Egypt; ${ }^{4}$ Animal Health Research Institute, Dokki, Giza.

\begin{abstract}
Background and objective: Bovine theileriosis is a global tick-borne disease and it has emerged as one of the major constraints affecting livestock production in Egypt. The disease is caused by the hemoparasite, Theileria annulata, which is transmitted by the tick vector, Hyalomma species. Materials and methods: A total of 376 Egyptian female Balady-Friesian cross cattle were randomly selected in El-Wadi El-Gadid province, Egypt and were examined using microscopic examination of Giemsa-stained thin blood smears and PCR-dependant molecular identification using a Theileria annulata-specific primer pair, Cytob1,targeting the amplicon of $312 \mathrm{bp}$ of the mitochondrial cytochrome b gene. Results: It has been found that $102(27.13 \%)$ animals had clinical symptoms of piroplasmosis, predominantly enlargement of superficial lymph nodes and a sustainable high fever $\left(40-42^{\circ} \mathrm{C}\right)$, anorexia, loss of generalized conditions, lacrimation, corneal affections, ocuo-nasal discharge, dyspnea and diarrhea. Light microscopy of Giemsa-stained thin blood smears revealed that 35 (9.31\%) of examined animals showed the presence of intra-lymphocytic and/or intra-erythrocytic stages of hemoparasites. Various stages including macroschizonts, microschizonts and merozoites were demonstrated in thin blood smears. Application of PCR elucidated that $11.44 \%$ (43/376)animals had theileriosis indicated by the appearance of specific diagnostic bands. Most of clinically-positive animals and all those positive by the use of microscopic examination and PCR are associated with the existence of ticks vector. Conclusion: The present work revealed the prevalence of bovine theileriosis in El-Wadi El-Gadid, Egypt using microscopic examination of Giemsa-stained thin blood smears (9.31\%) and PCR (11.44\%).To reduce economic losses induced in cattle due to theileriosis, a considerable attention and veterinary care are mandatory to be done by authorities and veterinarians through elimination of the tick vectors and frequent treatment of infected animals.
\end{abstract}

Keywords | Cattle, Theileria annulata, Hyalomma spp., PCR, Egypt.

Editor | Muhammad Imran Rashid, Department of Parasitology, University of Veterinary and Animal Sciences, Lahore, Pakistan.

Received | April 30, 2018; Accepted | May 28, 2018; Published | June 25, 2018

*Correspondence | Khaled Mohamed El-Dakhly, Department of Parasitology, Faculty of Veterinary Medicine, Beni-Suef University, Beni-Suef 62511, Egypt; Email: eldakley_s71@yahoo.com

Citation | El-Dakhly Kh M, Arafa W, Ghanem SS, Abdel-Fatah OR, Wahba AA (2018). Microscopic and molecular detection of theileria annulata infection of cattle in Egypt. J. Adv. Parasitol. 5(2): 29-34.

DOI | http://dx.doi.org/10.17582/journal.jap/2018/5.2.29.34

Copyright $\odot 2018$ El-Dakhly et al. This is an open access article distributed under the Creative Commons Attribution License, which permits unrestricted use, distribution, and reproduction in any medium, provided the original work is properly cited.

\section{INTRODUCTION}

$\mathrm{L}$ ivestock, particularly cattle and buffaloes as well as

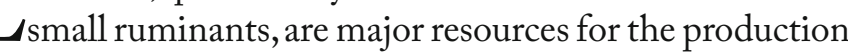
of milk and meat through a wide belt of tropical and subtropical areas (Nayel et al., 2012). The productivity of such animals is known to be greatly diminished by tick-borne parasitic diseases, particularly babesiosis and theileriosis, causing considerable economic losses on both local and global scales with several complications (Uilenberg, 1995;
Ahmed et al.,2002; Al-Saeed et al.,2010; Elsify et al.,2015). Theileriosis is serious hemoparasitic tick-borne disease caused by the apicomplexan, Theileria parasites, infecting a variety of wild and domestic animals and is transmitted trans-stadially by the tick vectors (Preston, 2001; Silva et al., 2010; Nayel et al., 2012). Theileria annulata causes tropical theileriosis, a disease transmitted by ticks of the genus Hyalomma (Uilenberg, 1981; El-Deeb and Younis, 2009) in North African countries, particularly Egypt (Gharbi et al., 2013; Ayadi et al., 2016). The protozoan is often 
present in areas in which the tick species are predominant including a wide range of tropical and subtropical areas, particularly African countries (Purnell, 1978). Accordingly, the disease is commonly proved in northern Africa and Sudan the Middle East, Central Asia, China, India, southern Europe and southern Russia where more than 250 million cattle are estimated to be at risk (McCosker, 1979; Robinson, 1982).

Traditionally, the diagnosis of Theileria parasites is based on the clinical symptoms and the detection of morphological characters of piroplasms inside red blood cells in Giemsa-stained thin blood smears (Latif et al., 1977; Muslih et al., 1988). However, such technique is only reliable for the diagnosis in acute cases and has limited value in subclinical cases due to a low parasitemia, when few numbers of piroplasms could be detected in the peripheral blood. Furthermore, high experts are demanded to accurately differentiate among various pathogenic and non-pathogenic piroplasms (A1-Saeed et al., 2010). However, since antibodies may still circulating for some time after the parasite has been cleared from the diseased animals, serological techniques do not often provide information about the actual existence of the parasite associated with the high opportunity of false data as a result of the cross reactions and the weak immune response (Passos et al., 1998; Nayel et al., 2012). The development of molecular techniques has made accurate tools for the detection of the parasite DNA. Such methods are appropriate and successful in neighboring countries which have a similar topographical nature to Egypt; Tunisia (M'ghirbi et al., 2008), United Arab Emirates (Jaffar et al., 2010) and Iran (Zaeemi et al., 2011). The first polymerase chain reaction (PCR) applied for the diagnosis of $T$. annulata in the bovine hosts was based on the Tams 1 gene (d'Oliveira et al.,1995).

Therefore, the present study was designed to detect the current prevalence of the infection with the hemoparasites, Theileria annulata, of cattle in El-Wadi El-Gadid, Egypt. Assessment is based on clinical symptoms, microscopic examination of Giemsa-stained thin blood smears and PCR-molecular diagnosis using the specific primer pair targeting the mitochondrial cytochrome $b$ gene.

\section{MATERIALS AND METHODS}

\section{The Study Area and Animals}

A total of 376 Egyptian female Balady-Friesian cross cattle admitted to different veterinary clinics in El-Wadi El-Gadid province (coordinates: $24^{\circ} 32^{\prime} 44^{\prime \prime} \mathrm{N}, 27^{\circ} 10^{\prime} 24^{\prime \prime} \mathrm{E}$ ) in the south-western part of Egypt, were examined for the detection of Theileria parasites. Available data concerning the general conditions of animals, the past history of infection, the existence of tick species, clinical symptoms, and other infections were accurately recorded.

\section{Blood Sampling}

Blood samples were collected for both microscopic examination and PCR (with anticoagulant, sodium salt of EDTA). Blood was collected from the jugular vein and immediately preserved in Eppendorf tubes containing a few drops of EDTA (Hamed et al., 2011).

\section{Microscopic Examination}

Thin blood smears were fixed in methanol (99.5\%) for 5 min and stained for $30 \mathrm{~min}$ in Giemsa solution diluted with $5 \%$ buffer. Slides were examined for the presence of intracellular hemoparasites. The smears were recorded as negative for piroplasms if no parasites were detected in 50 oil-immersion fields (Moretti et al., 2010).

\section{DNA ExTRACTION}

DNA was extracted from the blood specimens according to the manufacturer instructions (Sivakumar et al., 2012). Briefly, DNA was extracted from $200 \mu$ of the whole blood from individual cattle using a commercial $g S Y N{ }^{\mathrm{TM}} \mathrm{DNA}$ extraction kit (Cat. No.GS050) (Geneaid, New Taipei, Taiwan). DNA samples were stored at $-20^{\circ} \mathrm{C}$ until use.

\section{PCR Amplification}

DNA extracted from blood samples obtained from Theileria-infected cattle were used for PCR with the use of a specific primer pair,Cytob1, forward (F) 5'-ACTTTGGCCGTAATGTTAAAC-'3 and reverse (R) 5'-CTCTGGACCAACTGTTTG G-'3 (Belgic et al., 2010) targeting the amplicon of $312 \mathrm{bp}$ of the mitochondrial cytochrome $\mathrm{b}$ gene.Accordingly, $12.5 \mu 12 \mathrm{X}$ master mix (Geneaid Biotech Ltd., New Taipei, Taiwan), $1 \mu \mathrm{l}$ 1F (10 pmol/ $\mu \mathrm{l}), 1 \mu \mathrm{R}$ (10 pmol/ $\mu 1$ ), $3 \mu \mathrm{DNA}$ sample, and $7.5 \mu \mathrm{l}$ nuclease free water were mixed in a total volume of $25 \mu$. PCR cycling started with an initial denaturation for $5 \mathrm{~min}$ at $95^{\circ} \mathrm{C}$ followed by 37 cycles of denaturation for 30 second at $95^{\circ} \mathrm{C}$, annealing for 60 second at $52^{\circ} \mathrm{C}$, and elongation for $1 \mathrm{~min}$ at $72^{\circ} \mathrm{C}$. The final extension occurred at $72^{\circ} \mathrm{C}$ was allowed to proceed for $7 \mathrm{~min}$. PCR amplicons were electrophoresed on $1.5 \%$ agarose gel with ethidium bromide and photographed using a transilluminator.

\section{RESULTS}

Among 376 examined Balady-Friesian cross cattle, 102 (27.13\%) animals had clinical symptoms of piroplasmosis, predominantly enlargement of superficial lymph nodes, particularly parotid, prescapular, and prefemoral lymph nodes, as well as a sustainable high fever $\left(40-42^{\circ} \mathrm{C}\right) \mathrm{ex}^{-}$ tended along the course of infection. Other clinical symptoms including anorexia, loss of generalized conditions, 
lacrimation, corneal affections, ocuo-nasal discharge and diarrhea were consistent (Figure 1).

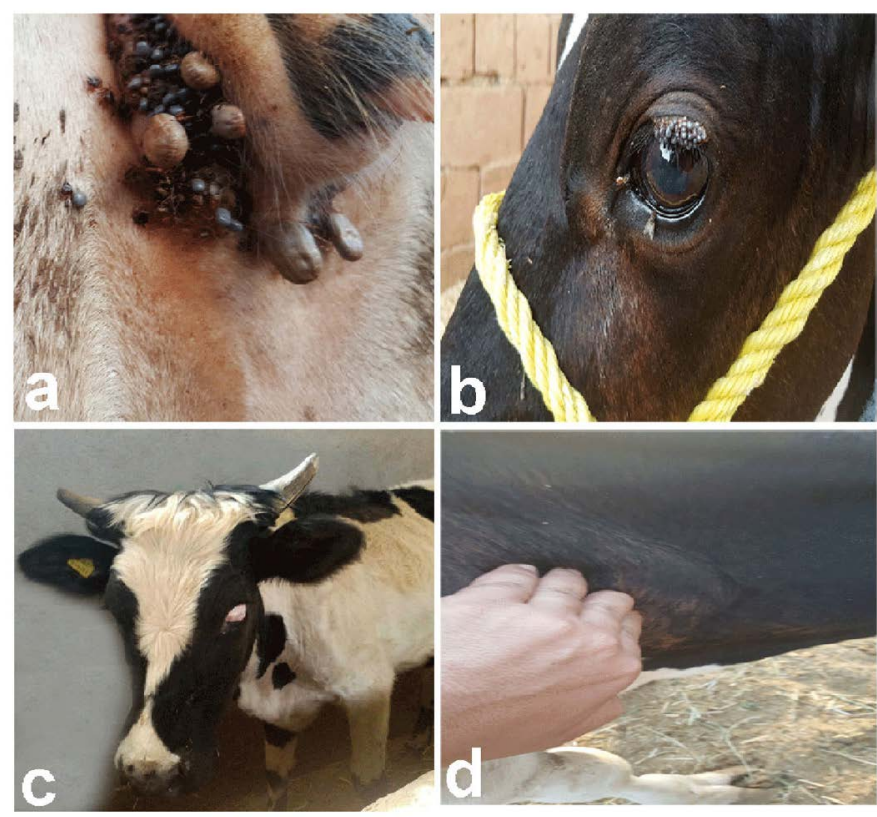

Figure 1: Clinical symptoms of theileriosis in examined Balady-Friesian cattle in Egypt. a) The perineal area of an infected animal heavily infected with tick species. b) An eye of Theileria-infected cattle showing ticks infestations. c) Severe bovine ocular affections. d) Enlargement of superficial lymph nodes

Among clinically infected cattle, light microscopy of Giemsa-stained thin blood smears revealed that 35(9.31\%) specimens showed the presence of intra-lymphocytic and/ or intra-erythrocytic stages of hemoparasites. As a result of multiplication of Theileria parasites, both macroschizonts (Figure 2) and microschizonts were found in most of clinically infected cattle. The appearance of a high fever and the generalized lymphadenopathy in such animals proved the infection. Meanwhile, some infected cattle exhibited ruptured schizonts due to prolonged infection. Sporadically, infected red blood cells might contain individual merozoites.

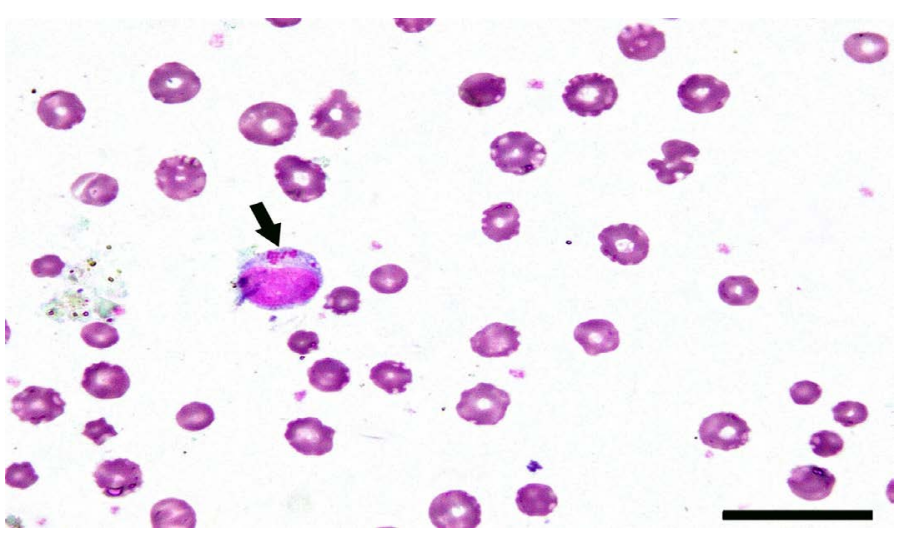

Figure 2: Bovine lymphocytes infected with Theileria parasites. Arrow referred to macroschizont. Scale bar $=20$ $\mu \mathrm{m}$

June 2018 | Volume 5 | Issue 2 | Page 31
Application of PCR using a specific primer pair,Cytob1, for Theileria annulata elucidated that 43(11.44\%) animals had theileriosis targeting the amplicon of $312 \mathrm{bp}$ (Figure 3). Diagnostic bands proved the bovine theileriosis.

$\begin{array}{lllllllllllll}M & 1 & 2 & 3 & 4 & 5 & 6 & 7 & 8 & 9 & 10 & 11 & 12\end{array}$

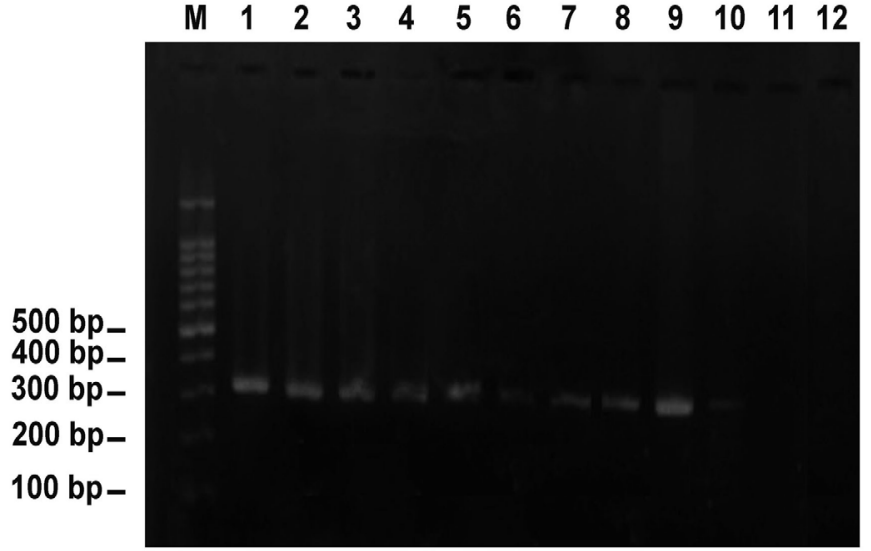

Figure 3: PCR amplification of DNA extracted from blood specimens of Theileria-infected cattle using the specific primer pair, Cytob1, targeting the mitochondrial cytochrome b gene. Note the diagnostic band appeared as 312 bp. Lane M revealed 100-bp ladder= DNA marker. Lanes 1-10 indicated 10 positive animals (animals are numbered as 23, 44, 56, 60, 76, 85, 91, 92, 93 and 98, respectively). Lanes 11 and 12 indicated negative animals (animals numbered 18 and 79)

It is worth mentioning that most of clinically-positive animals and all those positive by the use of microscopic examination and PCR are associated with the abundance of ticks vector. Highly feverish animals and those with enlarged lymph nodes were heavily parasitized by ticks. Application of both traditional and molecular tools is useful in diagnosis of infection, particularly in subclinical cases.

\section{DISCUSSION}

In the current study, Egyptian Balady-Friesian cattle, bred in different farms and admitted to veterinary clinics in El-Wadi El-Gadid province, were surveyed for tropical theileriosis. Subsequently, cattle underwent both traditional diagnosis, by the use of light microscopy of Giemsa-stained thin blood smears, and a molecular technique, using a specific primer pair.

The present investigation revealed that $9.31 \%$ of examined cattle had Theileria parasites using Giemsa-stained thin blood films. In Egypt, several studies investigated the prevalence of Theileria parasites in cattle. Among those, Abdel-Radyet al. (2008) detected that out of 120 cattle, 31 (25.8\%) animals in Assiut, Sohage and El-Wadi El-Gadid provinces harboured T. annulata parasites in Giemsa-stained thin blood smears. Moreover, Abdel-Rady et al. (2010) revealed an infection rate of $65.6 \%$ by micro- 
scopic examination of thin blood smears in cattle examined in El-Wadi EL-Gadid, Assiut, El-Fayoum, El-Minia and Sohage provinces. In both reports, theileriosis might be related to the predominance of the vector, Hyalomma species, however, in the second study, the higher infection rate could be attributed to the use of microscopic examination for such animals in the early acute stage allowing great opportunities for both intracellular piropalsms and lymphocytic Koch's blue bodies. Furthermore, Al-Hosary et al. (2015) found that Giemsa-stained thin blood smear revealed $30.98 \%$ cattle $(145 / 468)$ positive for theileriosis in El-Wadi El-Gadid. Several reports in such province indicated the abundance of Hyalomma ticks which encouraged in the hot climate, the main topographical feature of El-Wadi El-Gadid province. Meanwhile, Elsify et al. (2015) recorded an infection rate of $9.56 \%$ with Theileria annulata in cattle in Menoufia, Behera, Giza and Sohage provinces, Egypt by the use of light microscopy of Giemsa-stained thin blood smears. In a similar African country, Algeria, Ayadi et al. (2016) demonstrated that the percentages of Theileria-positive Giemsa-stained thin blood smears, before and after the tick season, were $10.4 \%$ and $16.4 \%$, respectively.

In the current work, two techniques were used for the diagnosis of T. annulata, microscopic examination of Giemsa-stained thin blood smears and PCR. In the former, the number of infected blood cells increases during the acute (early) infection, allowing an ease appearance of intracellular trophozoites and, consequently, a reliable detection of the parasite by microscopic examination in Giemsa-stained thin blood smears. It is well known that PCR is more sensitive and specific than traditional methods. Accordingly, authors noticed that microscopic examination of thin blood smears might be useful in acute infections of theileriosis. However, establishment of the immune response drastically decreases the number of infected erythrocytes. Moreover, during the tick season, the cattle immune system is enhanced by further infections leading to a consequent decline in sensitivity of such traditional method (Ayadi et al., 2016). Several studies reported that PCR is more sensitive and specific than microscopic examination of Giemsa-stained thin blood smears for detecting bovine theileriosis, particularly in carrier animals (Azizi et al., 2008; Safarpoor Dehkordi et al., 2012; Ayadi et al., 2016).

Currently, PCR-based technique using T. annulata-specific primer pair, Cytob1, reported that $11.44 \%$ of animals were theileriosis-positive and had specific diagnostic bands at $312 \mathrm{bp}$. Similarly, Ibrahim et al. (2009) revealed the percentages of PCR-positive animals for Theileria annulata were 13\% (7/54). Moreover, Elsify et al. (2015) detected that $T$. annulata was found in $9.56 \%$ of examined bovine blood samples using PCR in Behera, Giza, and Sohag provinces, Egypt. On the other hand, Abdel Rady et al. (2010), in E1-Wadi El-Gadid, Assiut, El-Fayoum, El-Minia and Sohage provinces, recorded that the sensitivity of PCR using Tams 1 primer pair was $58.3 \%$. Meanwhile, in the same province, El-Wadi El-Gadid, Al-Hosary et al. (2015) revealed that Tams 1 primer-based PCR proved Theileria annulata infection in 343 (73.29\%) out of 468 bovine blood specimens. The discrepancy from the present study might be referred to the intensity of ticks infestation. Similar to the current results, Hoghooghi-Rad et al. (2011) found that the semi-nested PCR accurately revealed 12 (7.5\%) positive bovine blood specimens in Golestan province of Iran. In Banaskantha district, India, Chauhan et al. (2015) recorded that $24(46.15 \%)$ cows were infected with $T$. annulata using Tams1 gene-based PCR. Concomitantly, Acharya et al. (2017) recovered 68\% (34/50) infection rate of theileriosis in cattle in Odisha, India using PCR. In Europe, Brigido et al. (2004) applied PCR on bovine blood and revealed that $3(2.57 \%)$ out of 116 specimens were infected with Theileria and/or Babesia parasites.

In conclusion, the present investigation has emerged tropical theileriosis, due to Theileria annulata, by the use of both traditional methods, microscopic examination of Giemsa-stained thin blood smears, and a molecular assay, conventional PCR based on the use of T. annulata-specific primer pair targeting the mitochondrial cytochrome $b$ gene (312 bp) in El-Wadi El-Gadid, Egypt. It is worthy to mention that cattle of local breeds are generally more resistant than exotic animals, explaining that the infection rate in the current breed, Balady-Friesian species, is lower than imported species. For a proper control of theileriosis, it is advisable to apply the appropriate acaricides together with eradication of tick vectors. In such concern, sealing of cracks and plastering and smoothing the inner and outer walls of animal stables could reduce the survival of ticks vector.

\section{ACKNOWLEDGEMENTS}

Authors would like to thank the veterinarians and owners who facilitate both admission of animals and blood sampling in El-Wadi El-Gadid, Egypt.

\section{CONFLICT OF INTEREST}

There are no conflicts of interest.

\section{AUTHORS CONTRIBUTION}

Experimental design and ideas developed by Khaled Mohamed El-Dakhly. Data and samples collection by Saad Soliman, Omima Abdel-Fatah and Ahmed Anwar. Lab analysis by Waleed Arafa and Khaled Mohamed El-Dakhly. Manuscript preparation by Khaled Mohamed El-Da- 
khly.

\section{REFERENCES}

- Abdel-Rady A, Ahmed LS, Mohamed A, Al-Hosary A (2010). Using polymerase chain rreaction (PCR) for diagnosis of bovine theileriosis in Upper Egypt. Int. J. Agro. Vet. Med. Sci. 4 (3):67-74.

-Abdel-Rady A, Kotb S, AbdEllah MR (2008). Clinical, diagnostic and therapeutic studies on theileriasis (Theileria annulata) in cattle in Upper Egypt. Suez Canal Vet. Med. J. 13 (2):378-395.

- Acharya AP, Panda SK, Prusty BK (2017). Diagnosis and confirmation of Theileria annulata infection in cattle in Odisha, India. J. Entomol. Zool. Stud. 5(4): 1543-1546.

- Ahmed JS, Yin H, Schnittger L, Jongejan F (2002). Ticks and tick-borne diseases in Asia with special emphasis on China. Parasitol. Res. 88: 51-55. https://doi.org/10.1007/s00436001-0574-3

- Al-Hosary AAT, Ahmed J, Nordengrahn A, Merza M (2015). Assessment of the First commercial ELISA Kit for the diagnosis of Theileria annulata. J. Parasitol. Res. Volume 2015, Article ID 787812, 4 pages. http://dx.doi. org/10.1155/2015/787812

-Al-Saeed ATM, Omer LT, Abdo J, Habibi G, Salih DA, Seitzer U, Ahmed J (2010). Epidemiological studies on tropical theileriosis (Theileria annulata infection of cattle) in Kurdistan Region, Iraq. Parasitol. Res. 106: 403-407. https://doi.org/10.1007/s00436-009-1675-7

- Ayadi O, Rjeibi MR, Elfegoun MCB, Gharbi M (2016). Prevalence and risk factors of tropical theileriosis, and sequencing of Theileria annulata, the causative pathogen, in Setif region (Algeria) before and after tick season. Rev. Elev. Med. Vet. Pays. Trop. 69 (4): 161-166. https://doi. org/10.19182/remvt.31201

- Azizi H, Shiran B, Farzaneh Dehkordi A, Salehi F, Taghadosi C (2008). Detection of Theileria annulata by PCR and its comparison with smear method in native carrier cows. Biotechnology. 7 (3): 574-577. https://doi.org/10.3923/ biotech.2008.574.577

- Bilgic HB, Karagenc T, Shiels B, Tait A, Eren H, Weir W (2010). Evaluation of cytochrome b as a sensitive target for PCR based detection of T. annulata carrier animals. Vet. Parasitol.174: 341-347. https://doi.org/10.1016/j. vetpar.2010.08.025

- Brigido C, Da Fonseca IP, Parreira R, Fazendeiro I, do Rosário VE, Centeno-Lima S (2004). Molecular and phylogenetic characterization of Theileria spp. parasites in autochthonous bovines (Mirandesa breed) in Portugal. Vet. Parasitol. 123: 17-23. https://doi.org/10.1016/j.vetpar.2004.05.024

- Chauhan HC, Patel BK, Bhagat AG, Patel MV, Patel SI, Raval SH, Panchasara HH, Shrimali MD, Patel AC, Chandel BS (2015). Comparison of molecular and microscopic technique for detection of Theileria annulata from the field cases of cattle. Vet. World. 8(11): 1370-1374. https://doi. org/10.14202/vetworld.2015.1370-1374

- d' Oliveira C, van der Weide M, Habela MA, Jacquiet P, Jongejan F (1995). Detection of Theileria annulata in blood samples of carrier cattle by PCR. J. Clin. Microbiol. 13:2665-2669.

- El-Deeb WM, Younis EE (2009). Clinical and biochemical studies on Theileria annulata in Egyptian buffaloes (Bubalus bubalis) with particular orientation to oxidative stress and ketosis relationship. Vet. Parasitol. 164: 301-305. https:// doi.org/10.1016/j.vetpar.2009.06.002

- Elsify A, Sivakumar T, Nayel M, Salama A, Elkhtam A, Rizk M, Mosaab O, Sultan K, Elsayed S, Igarashi I, Yokoyama N (2015). An epidemiological survey of bovine Babesia and Theileria parasites in cattle, buffaloes, and sheep in Egypt. Parasitol. Int. 64(1): 79-85. https://doi.org/10.1016/j. parint.2014.10.002

- Gharbi M, Hayouni ME, Sassi L, Dridi W, Darghouth MA (2013). Hyalomma scupense (Acari, Ixodidae) in northeast Tunisia: seasonal population dynamics of nymphs and adults on field cattle. Parasite. 20, e12. https://doi.org/10.1051/ parasite/2013012

- Hamed MI, Zaitoun AMA, El-Allawy TAA, Mourad MI (2011). Investigation of Theileria camelensis in camels infested by Hyalomma dromedarii ticks in Upper Egypt. J. Adv. Vet. Res.1: 4-7.

-Hoghooghi-Rad N, Ghaemi P, Shayan P, Eckert B ,SadrShirazi N (2011). Detection of native carrier cattle infected with Theileria annulata by semi-nested PCR and smear method in Golestan province of Iran. World Appl. Sci. J. 12 (3): $317-323$.

- Ibrahim AK, EL Behairy AM, Mahran KA, Awad WS (2009). Clinical and laboratory diagnosis of piroplasmids in naturally infected cattle in Egypt. J. Egyptian Vet. Med. Assoc. 69(2): 191-203.

- Jaffer O, Abdishakur F, Hakimuddin F, Riya A, Wernery U, Schuster RK (2010). A comparative study of serological tests and PCR for the diagnosis of equine piroplasmosis. Parasitol Res. 106(3): 709-713. https://doi.org/10.1007/ s00436-009-1669-5

- Latif BM, Hawa NJ, Bakir FA (1977). Incidence of malignant theileriosis (Theileria hirci) of sheep in Iraq. Iraqi J. Vet. Med. 1:29-37.

- McCosker PI (1979). Global aspects of the management and control of ticks of veterinary importance. Rec. Adv. Acarol. 11, 45-53. https://doi.org/10.1016/B978-0-12-5922029.50012-4

- M'ghirbi Y, Hurtado A, Brandika JF, Khlif K, Ketata Z, Bouattour A (2008). A molecular survey of Theileria and Babesia parasites in cattle, with a note on the distribution of ticks in Tunisia. Parasitol. Res. 103: 435-442. https://doi. org/10.1007/s00436-008-0995-3

- Moretti A, Mangili V, Salvatori R, Maresca C, Scoccia E, Torina A, Moretta I, Gabrielli S, Tampieri MP, Pietrobelli M (2010). Prevalence and diagnosis of Babesia and Theileria infections in horses in Italy: a preliminary study. Vet. J. 184:346-350. https://doi.org/10.1016/j.tvj1.2009.03.021

- Muslih NJ, Zangana IK, Arsalan SH (1988). Incidence of various clinical diseases in sheep and goats in north Iraq (Mosul). Int. J. Anim. Sci. 3:157-163.

- Nayel M, El-Dakhly Kh M, Aboulaila M, Elsify A, Hassan H, Ibrahim E, Salama A,Yanai T (2012).The use of different diagnostic tools for Babesia and Theileria parasites in cattle in Menofia, Egypt. Parasitol. Res. 111:1019-1024. https://doi. org/10.1007/s00436-012-2926-6

- Passos LM, Bell-Sakyi L, Brown CG (1998). Immunochemical characterization of invitro culture-derived antigens of Babesia bovis and Babesia bigemina. Vet. Parasitol. 76: 239249. https://doi.org/10.1016/S0304-4017(98)00095-8

- Preston PM (2001). Theilerioses. In: Wallingford MW (eds). Encyclopedia of Arthropod transmitted Infections of Man and Domesticated Animals, CABI Publishing, Pp 487-502. 
- Purnell RE (1978). Theileria annulata as a hazard to cattle in countries in the northern Mediterranean littoral. Vet. Sci. Commun. 2: 3-10. https://doi.org/10.1007/BF02291428

- Robinson PM (1982). Theileriosis annulata and its transmission - A review. Trop. Anim. Health Prod.14: 3-12. https://doi. org/10.1007/BF02281092

- Safarpoor Dehkordi F, Parsaei P, Saberian S, Moshkelani S, Hajshafiei P, Hoseini SR, Babaei M, Ghorbani MN (2012). Prevalence study of Theileria annulata by comparison of four diagnostic techniques in southwest Iran. Bulg. J. Vet. Med. 15 (2): 123-130.

- Silva MG, Marques PX, Oliva A (2010).Detection of Babesia and Theileria species infection in cattle fromPortugal using a reverse line blotting method. Vet. Parasitol.174: 199-205. https://doi.org/10.1016/j.vetpar.2010.08.038

- Sivakumar T, Altangerel K, Battsetseg B, Battur B, AbouLaila M, Munkhjargal T, Yoshinari T, Yokoyama N, Igarashi I (2012). Genetic detection of Babesia bigemina from
Mongolian cattle using apical membrane antigen-1 gene based PCR assay. Vet .Parasitol. 187: 17-22. https://doi. org/10.1016/j.vetpar.2012.01.008

- Uilenberg G (1981). Theileria species of domestic livestock. In: Irvin AD, Cunningham, MP, Youn AS (eds) Advances in the control of theileriosis. Martinus Nijhoff Publishers, The Hague, Boston, London, pp. 4-37. https://doi. org/10.1007/978-94-009-8346-5_2

- Uilenberg G (1995). International collaborative research: significance of tick-Borne hemoparasitic diseases to world animal health. Vet. Parasitol. 57:19-41. https://doi. org/10.1016/0304-4017(94)03107-8

- Zaeemi M, Haddadzadeh H, Khazraiinia P, Kazemi B, Bandehpour M (2011). Identification of different Theileria species (Theileria lestoquardi, Theileria ovis, and Theileria annulata) in naturally infected sheep using nested PCRRELP.Parasitol.Res. 108: 837-843.https://doi.org/10.1007/ s00436-010-2119-0 